\title{
Obstacle Avoidance using Fuzzy Logic Controller on Wheeled Soccer Robot
}

\author{
Noorman Rinanto $^{1}$, Irfan Marzuqi ${ }^{2}$, Agus Khumaidi ${ }^{3}$, Sryang T. Sarena ${ }^{4}$ \\ ${ }^{1,2,3}$ Automation Engineering Study Program of Politeknik Perkapalan Negeri Surabaya, Surabaya, Indonesia \\ ${ }^{4}$ Marine Electrical Engineering Department of Shipbuilding Institute of Polytechnic Surabaya, Indonesia
}

\section{ARTICLE INFO}

\section{Article history:}

Received June 6, 2019

Revised July 7, 2019

Accepted July 11, 2019

\section{Keywords:}

Fuzzy logic

Soccer robot

Omnidirectional camera

Microcontroller

Obstacle avoidance

\begin{abstract}
The purpose of this study is to apply Fuzzy Logic Controller on a wheeled soccer robot to avoid the collision with other robots in the field. The robot equipped by an omnidirectional camera as a vision sensor, a mini-PC for the image processing device, a microcontroller to handle I/O system, and three wheel's omnidirectional mover system. Omni-camera produces four inputvalues, namely: $\mathrm{X}$ coordinate ball position, $\mathrm{Y}$ coordinate ball position, distance and angle from obstacle to the point of interest in the camera frame. These inputs processed by a mini-PC and then forward to a microcontroller to calculate the output using Fuzzy Logic Controller. The output variables are the movement rate of the robot in the $\mathrm{X}$, and $\mathrm{Y}$ coordinate. These outputs will be used by the kinematics controller to manage the speed of three Omniwheels driven by 24 volts DC motors. The experiment shows a good result with the percentage of the success of the robot catching the ball is around $70 \%$ and $80 \%$ in avoiding the obstacle. In time performance, the soccer robot with Fuzzy Logic Controller is superior by 4.67 seconds compared to the robot without this method.
\end{abstract}

Copyright $(0)$ 2019. Published by Universitas Ahmad Dahlan. All rights reserved

\section{Corresponding author:}

Noorman Rinanto,

Automation Engineering Study Program,

Politeknik Perkapalan Negeri Surabaya,

Teknik Kimia street, Keputih, Sukolilo, Surabaya, Indonesia

Email: noorman.rinanto@ppns.ac.id

\section{INTRODUCTION}

In recent years, robots have been a vital part of various human jobs. Many robots have been constructed to handle jobs that are too difficult for the human being. Dangerous jobs, complex works and human tasks that require high accuracy also need the help of intelligent and independent robots. Also, robots designed for entertainment and sports purposes such as soccer robots. These robots can walk using their legs or run on wheels. The primary distinction of those types is on their speed towards the ball and in evading the opponent. The wheeled robot is more superior on speed compared to legs ones. The speed could be difficult to control when the robot runs to avoid enemy players or friends. Therefore, this study focuses on wheel-driven soccer robots.

Indonesian Wheeled Soccer Robot Contest (KRSBI-Wheels) is a soccer robot competition using wheels for the college student that established since 2017. The rules of the game in the competition are similar to human football. Each competing robot team tries to put the ball into the opponent's goal as many as possible. The team that has a good ability to find the ball and move towards the ball will have more chances in winning the game. The efficient maneuver of the robot to avoid collisions with the opposing team or teammates is a problem that is not easy to be solved using conventional methods. Therefore, this study proposes to find a solution by implementing fuzzy logic control on soccer robots. There are several methods of Artificial Intelligent (AI) or modern control that are widely used in robotic by other researchers, such as Genetic Algorithm (GA) [1]-[3], Neural Network (NN) [4]-[6], and Fuzzy Logic [7]-[10]. The combination algorithm to control robot also proposed by several researchers [11]-[13].

In this research, fuzzy logic algorithms chosen for controlling the robot due to the ease and speed of the process compared with NN and GA [15]. Besides, research on the omnidirectional robot has implemented by 
Rabib H. A et al [14]. The input data of this system comes from the omnidirectional camera. This camera catches the environment image, and then it is processed by a mini-PC that will produce coordinate of the object. Later, a microcontroller will compute the coordinate using Fuzzy Logic Algorithm. The output of this plant will be used to control the movement speed of the robot.

\section{RESEARCH METHOD}

This section categorized into several parts, including system design, omnidirectional camera, and fuzzy logic controller implementation.

\subsection{Design of system}

The system design utilized the electronic component installed, as shown in Fig 1. The input of the system comes from two cameras connected to a mini PC (Odroid C2) that are used to process the image. The first camera is an omnidirectional camera to detect the ball and also the opponents at close range. This camera has the advantage of being able to see with a 360 degree viewing angle. The second camera is a web camera that is used to detect the ball and the opponents in front of the robot. These cameras work simultaneously for recognizing the ball and other obstacles. Data collected from cameras that are processed by a mini PC with programming based on the OpenCV Linux library.

Furthermore, the Mini PC produces the opponent's coordinate values (obstacles) and the ball position as the input of the Atmega2560 microcontroller. This hardware controller uses Fuzzy Logic algorithm to process the coordinate. That controlled the speed DC motor as actuators. Other sensors are added to the system to help to control the robot such as tilt sensor GY-25, proximity sensor for crash detection, and rotary encoder to count motor speed.

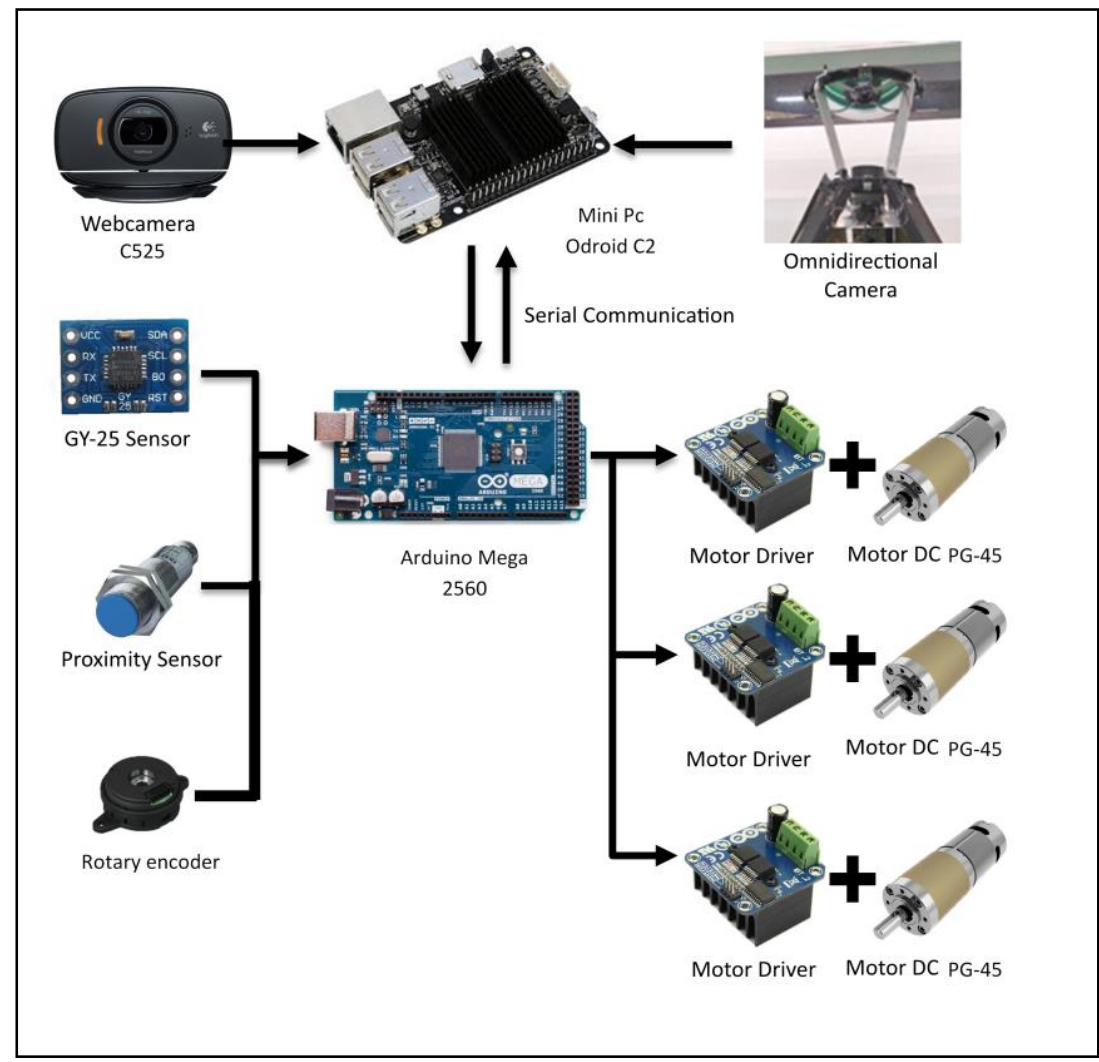

Fig. 1. Electronic system

Fig. 2 show the system process. In detail, vision captured the image of the object then converted RGB to HVS colour space, and using the threshold method to object segmentation process. By using the colour-based method that obtained the object feature, and uses to calculate the position the object. Fuzzy controlled that maintain coordinates for the Kinematic controller. The kinematic controller output is the PWM signal. Object detection in robot system obtained players distance, and ball position then coordinated of them. In this research, we used MATLAB Software to simulate the beta matrix and calculation of the testing process. 


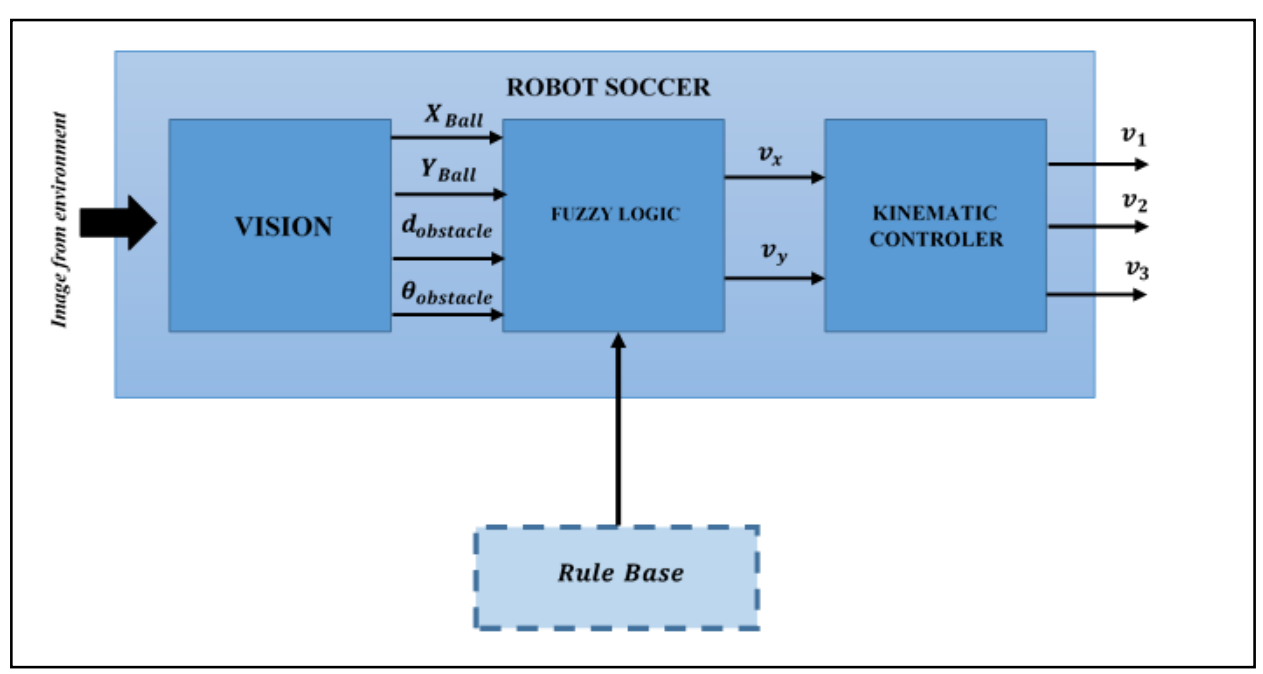

Fig. 2. Block diagram of the software

The side view of the robot design in this study, as shown in Fig. 3. It has $800 \mathrm{~mm}$ in height $\mathrm{x} 520 \mathrm{~mm}$ in width. The omnidirectional camera is installed on the highest position so that it can capture images with the widest view. This soccer robot is designed with conical shape to minimize blind spot, especially in the area close to the robot. The webcam installed in lower position from the first camera. These cameras have the primary task for seeking the ball in the front of the robot. While the robot design seen from above presented in Fig. 4.

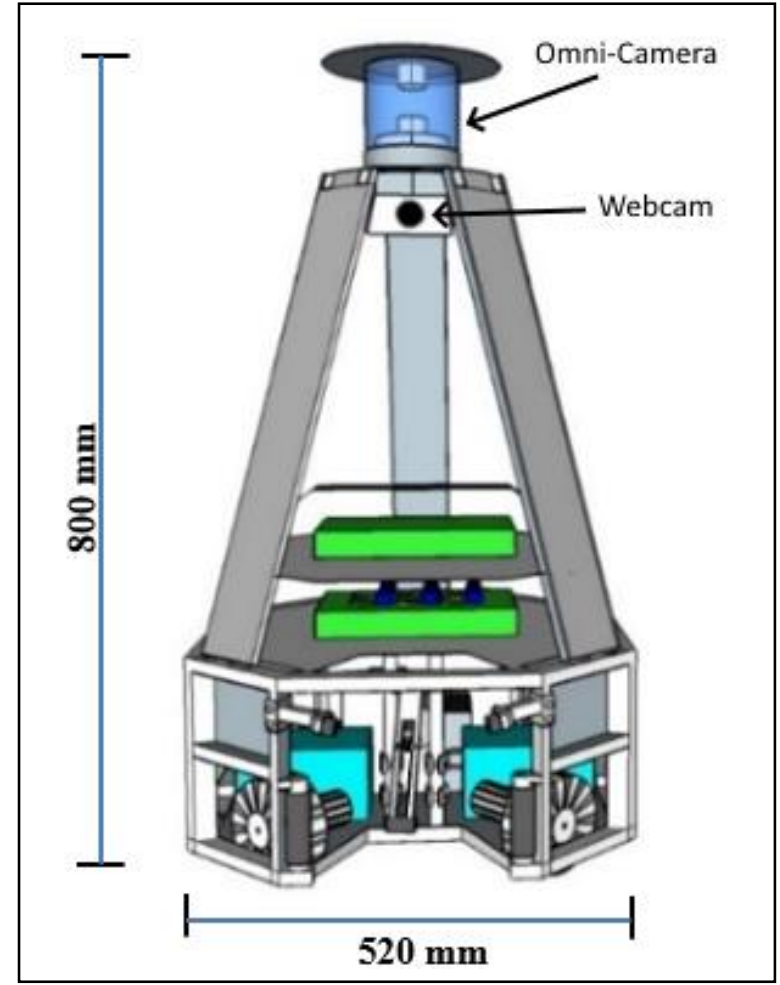

Fig. 3. The side view of the robot 


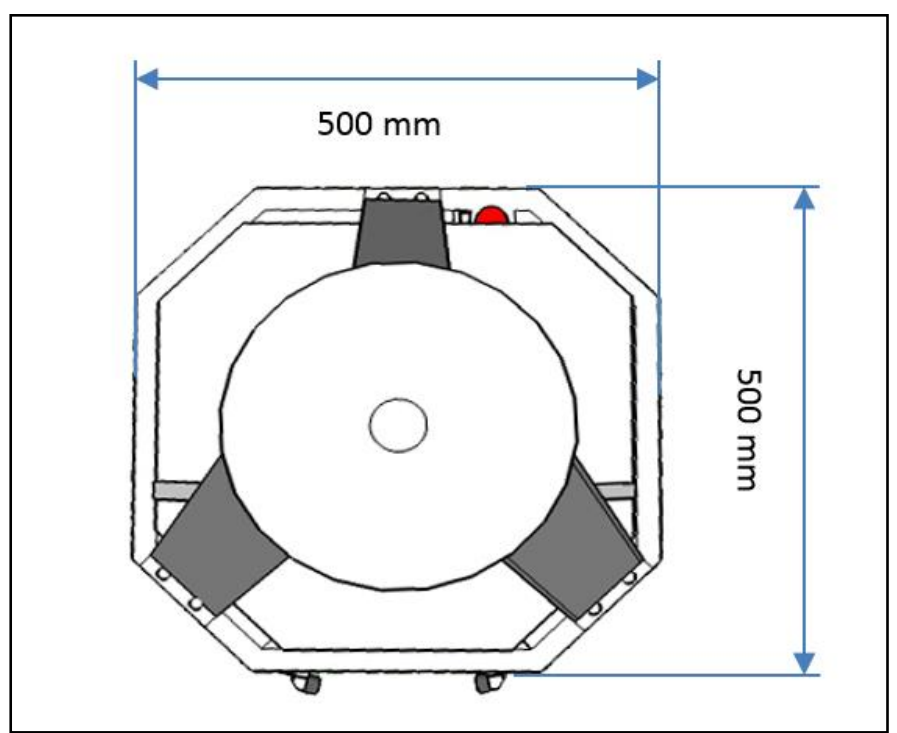

Fig. 4. The top view of the robot

This soccer robot built with a three omnidirectional driving system. This design consists of three DC motors arranged to form an angle of $120^{\circ}$ after each other, and the shaft of each DC motor mounted to the Omni wheel. The design of the drive system in this research illustrated in Fig. 5. With the motor placement as in the picture, it will obtain kinematics equations movement of robots as follows (1).

$$
\left[\begin{array}{l}
v_{1} \\
v_{2} \\
v_{2}
\end{array}\right]=\left[\begin{array}{lll}
-\sin \theta_{1} & \cos \theta_{1} & R \\
-\sin \theta_{2} & \cos \theta_{2} & R \\
-\sin \theta_{a} & \cos \theta_{3} & R
\end{array}\right]\left[\begin{array}{l}
v_{x} \\
v_{y} \\
v_{\theta}
\end{array}\right]
$$

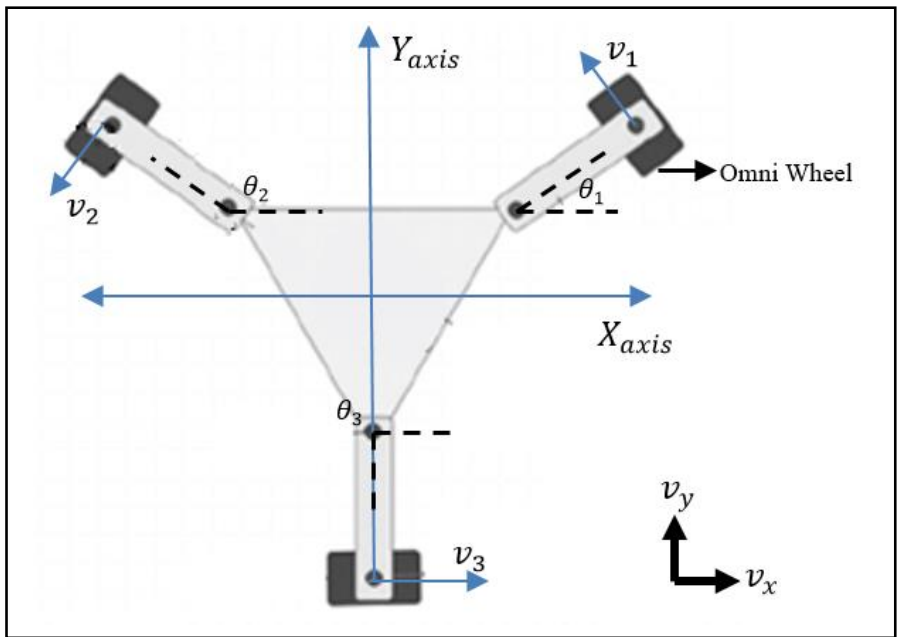

Fig. 5. Three-wheel omnidirectional driving system

\subsection{Omnidirectional camera}

Omnidirectional camera in this system composed of a hyperbolic mirror and a Logitech C525 camera which is mounted perpendicularly. The hyperbolic mirror is used for its capability to reflect images with a $360^{\circ}$ view. Logitech $\mathrm{C} 525$ that mounted at a certain distance below the hyperbolic mirror will capture reflected images from the mirror.

To protect the camera from external light interference that can affect the quality of the image result, a closing box installed around the camera. The construction of the omnidirectional camera displayed in Fig. 6. 


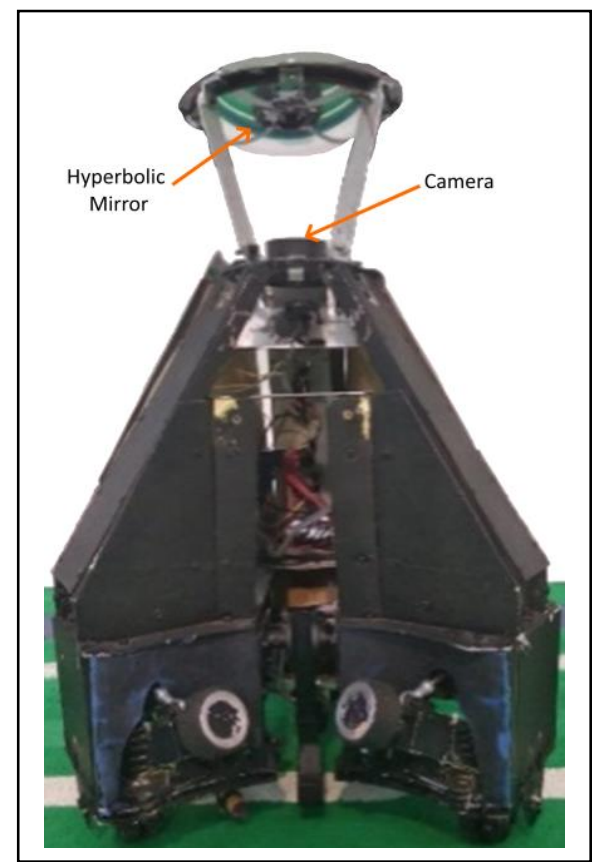

Fig. 6. Omnidirectional Camera construction

Fig. 7 represented a vision visualisation through the Omni-camera. Before the data from the Omnidirectional camera is proceed the microcontroller, shift the origin frame $(0,0)$ that divided into four different quadrants in the image frame. From the coordinate information of objects in the frame, we can obtain information about the distance and angle of the object to the robot using equations (2), (3). Where $d$ is object distance from the middle of the frame, $x$ is the object position in the X-axis, $y$ is the object point in the $\mathrm{Y}$, and $\theta$ is the object angle in the middle of the frame.

$$
\begin{aligned}
& d=\sqrt{x^{2}+y^{2}} \\
& \theta=\tan ^{-1} \frac{y}{x}
\end{aligned}
$$

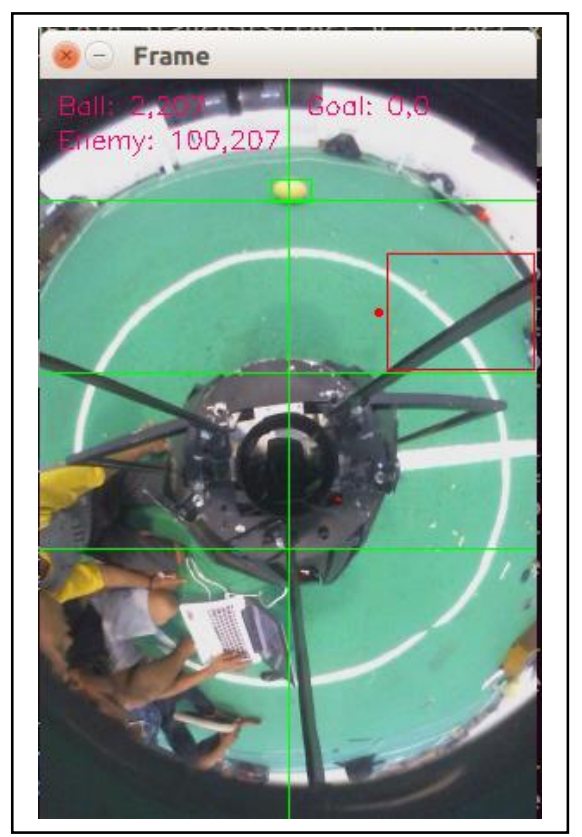

Fig. 7. Image reflection from hyperbolic mirror 


\subsection{Fuzzy logic controller implementation}

In this research, the fuzzy logic method used is zero-order fuzzy Sugeno where the input value is the position of the ball and the distance of the obstacle. The input data are taken from the omnidirectional camera, and the output is the speed variables in the $\mathrm{X}$-axis and $\mathrm{Y}$-axis. These variables used in kinematics controller to manage the PWM signal of three DC motors. The fuzzy control that proceeds the data input then calculated it by the microcontroller. Besides, the MATLAB software was used to design and simulate the fuzzy algorithm in the system. The simulate test that conducted uses fuzzification, determining the fuzzy rule base, and defuzzification to optimize parameters.

By the MATLAB software determined the fuzzy membership function, the robot has three input and two output and uses triangular and trapezoid models. The membership used such as Close (C), Medium (M), Far $(\mathrm{F})$, and Near $(\mathrm{N})$. To control the speed robot is changed the X-axis and Y-axis parameter. Besides, the membership of the output variable is used Very Fast, Fast, Medium, Slow, and Very Slow.

Fig. 8 to Fig.11 shows proposed the fuzzy membership function, then Table 1. provided the rule base applied to the robot system.

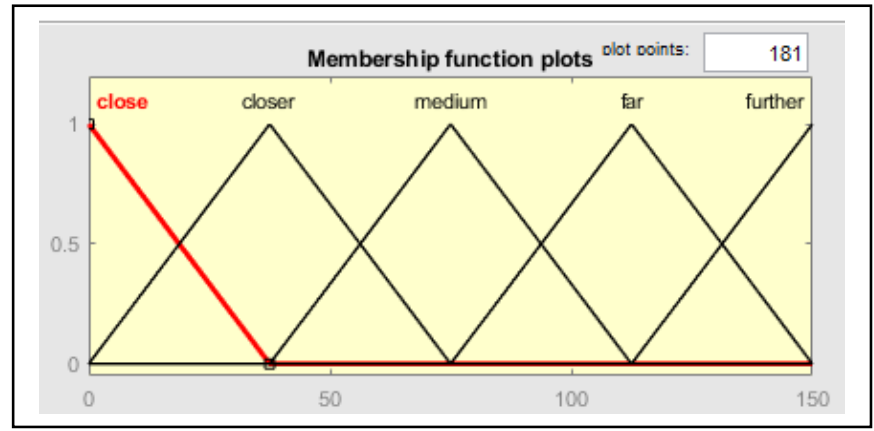

Fig. 8. Membership Function of Input $X_{B a l l}$ and $Y_{B a l l}$

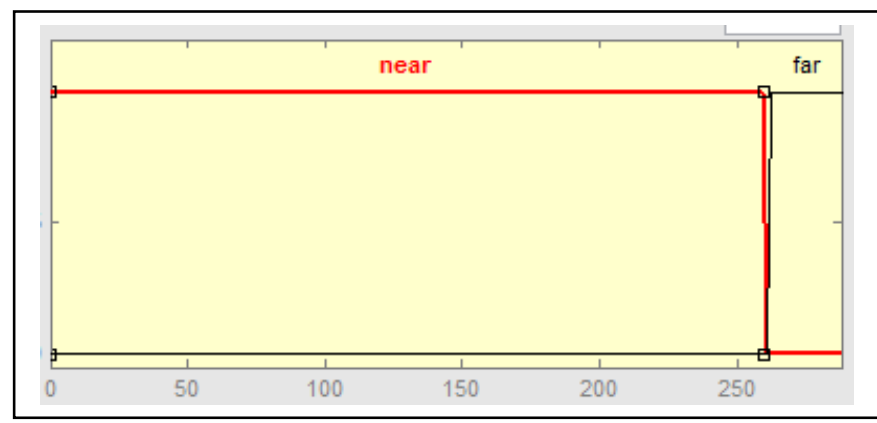

Fig. 9. The distance of the obstacle membership function

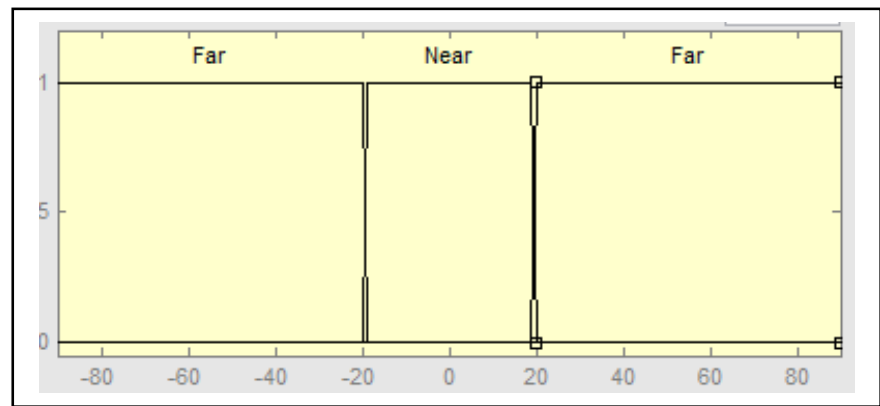

Fig. 10. The fuzzy membership of the obstacle angel 

Vol. 5, No. 1, Juni 2019, pp. 26-35

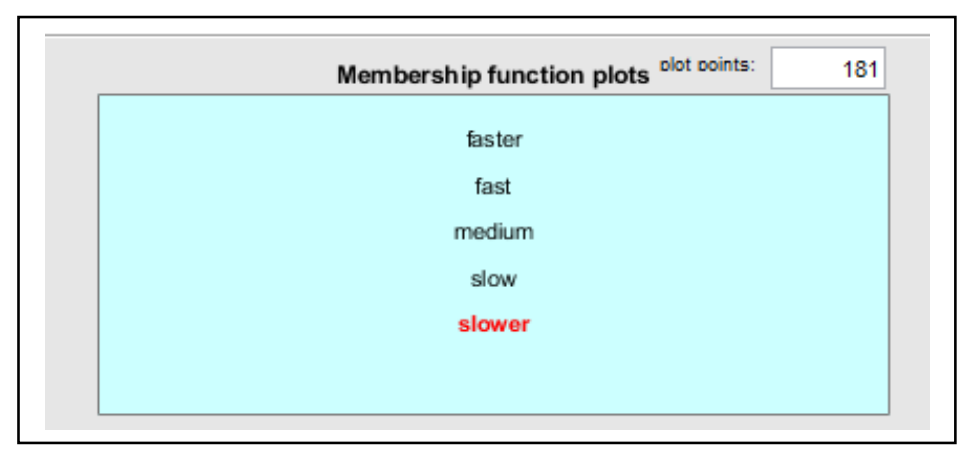

Fig. 11. The member output of fuzzy $v_{x}$ and $v_{y}$

Table 1. Fuzzy Logic Rule Base

\begin{tabular}{|c|c|c|c|c|c|c|}
\hline No & $X_{B a l l}$ & $Y_{B a l l}$ & $d_{\text {obs }}$ & $\theta_{\text {obss }}$ & $v_{x}$ & $\mathbb{v}_{y}$ \\
\hline 1 & Close & Close & Near & Near & Faster & Slower \\
\hline 2 & Close & Close & Near & Far & Fast & Slower \\
\hline 3 & Close & Close & Far & Near & Slower & Slower \\
\hline 4 & Close & Close & Far & Far & Slower & Slower \\
\hline 5 & Close & Medium & Near & Near & Faster & Slow \\
\hline 6 & Close & Medium & Near & Far & Fast & Medium \\
\hline 7 & Close & Medium & Far & Near & Slower & Medium \\
\hline 8 & Close & Medium & Far & Far & Slower & Medium \\
\hline 9 & Close & Far & Near & Near & Faster & Medium \\
\hline 10 & Close & Far & Near & Far & Fast & Fast \\
\hline 11 & Close & Far & Far & Near & Slow & Faster \\
\hline 12 & Close & Far & Far & Far & Slow & Faster \\
\hline 13 & Medium & Close & Near & Near & Faster & Slower \\
\hline 14 & Medium & Close & Near & Far & Fast & Slower \\
\hline 15 & Medium & Close & Far & Near & Medium & Slower \\
\hline 16 & Medium & Close & Far & Far & Medium & Slower \\
\hline 17 & Medium & Medium & Near & Near & Faster & Slower \\
\hline 18 & Medium & Medium & Near & Far & Fast & Slow \\
\hline 19 & Medium & Medium & Far & Near & Medium & Medium \\
\hline 20 & Medium & Medium & Far & Far & Medium & Medium \\
\hline 21 & Medium & Far & Near & Near & Faster & Slow \\
\hline 22 & Medium & Far & Near & Far & Faster & Slower \\
\hline 23 & Medium & Far & Far & Near & Medium & Faster \\
\hline 24 & Medium & Far & Far & Far & Medium & Faster \\
\hline 25 & Far & Close & Near & Near & Faster & Slower \\
\hline 26 & Far & Close & Near & Far & Faster & Slower \\
\hline 27 & Far & Close & Far & Near & Faster & Slow \\
\hline 28 & Far & Close & Far & Far & Faster & Slow \\
\hline 29 & Far & Medium & Near & Near & Fast & Slow \\
\hline 30 & Far & Medium & Near & Far & Fast & Medium \\
\hline 31 & Far & Medium & Far & Near & Faster & Medium \\
\hline 32 & Far & Medium & Far & Far & Faster & Medium \\
\hline 33 & Far & Far & Near & Near & Fast & Slow \\
\hline 34 & Far & Far & Near & Far & Fast & Medium \\
\hline 35 & Far & Far & Far & Near & Faster & Faster \\
\hline 36 & Far & Far & Far & Far & Faster & Faster \\
\hline
\end{tabular}

\section{RESULTS AND DISCUSSION}

The robot performance using fuzzy logic controller evaluated by the obstacle and the ball detection according to six positions. Additionally, to active the robot, an emergency button pushed. Table 2 shown performance of robot movement. We conducted ten times to test performance for obtaining the position.

Table 2. Fuzzy Logic performance results 

Vol. 5, No. 1, Juni 2019, pp. 26-35

\begin{tabular}{cllcc}
\hline No. & \multicolumn{1}{c}{ Ball Position } & \multicolumn{1}{c}{ Obstacle Position } & Avoiding Obstacle & Get The Ball \\
\hline 1 & $\begin{array}{l}\text { In front of and near } \\
\text { the robot }\end{array}$ & $\begin{array}{l}\text { In front of and near the } \\
\text { robot }\end{array}$ & $100 \%$ & $100 \%$ \\
2 & $\begin{array}{l}\text { In front of and far } \\
\text { from the robot }\end{array}$ & $\begin{array}{l}\text { In front of and far from } \\
\text { the robot }\end{array}$ & $100 \%$ & $100 \%$ \\
3 & $\begin{array}{l}\text { Left side and near the } \\
\text { robot }\end{array}$ & $\begin{array}{l}\text { Left side and near the } \\
\text { robot }\end{array}$ & $70 \%$ & $80 \%$ \\
4 & $\begin{array}{l}\text { Left side and far from } \\
\text { the robot }\end{array}$ & $\begin{array}{l}\text { Left side and far from } \\
\text { the robot }\end{array}$ & $80 \%$ & $80 \%$ \\
5 & $\begin{array}{l}\text { Right side and near } \\
\text { the robot }\end{array}$ & $\begin{array}{l}\text { Right side and near the } \\
\text { robot } \\
\text { Right side and far from } \\
\text { the robot }\end{array}$ & $70 \%$ & $70 \%$ \\
6 & $\begin{array}{l}\text { Right side and far } \\
\text { from the robot }\end{array}$ & $\mathbf{6 0 a n}$ & $70 \%$ \\
\hline
\end{tabular}

This research also is compared to robot trajectory performance by fuzzy logic controllers applied with normally controller. Fig. 12 illustrate the track of the robot without Fuzzy Algorithm to approaching the ball get through an obstacle. The robot has a collision with obstacles before touching the ball. However, Fig. 13 that shows the robot can avoidance the obstacle and reach the ball by the fuzzy controller. Table 3 described both test result in time performance. That shown an average time using fuzzy controller is faster than normally controller applied.

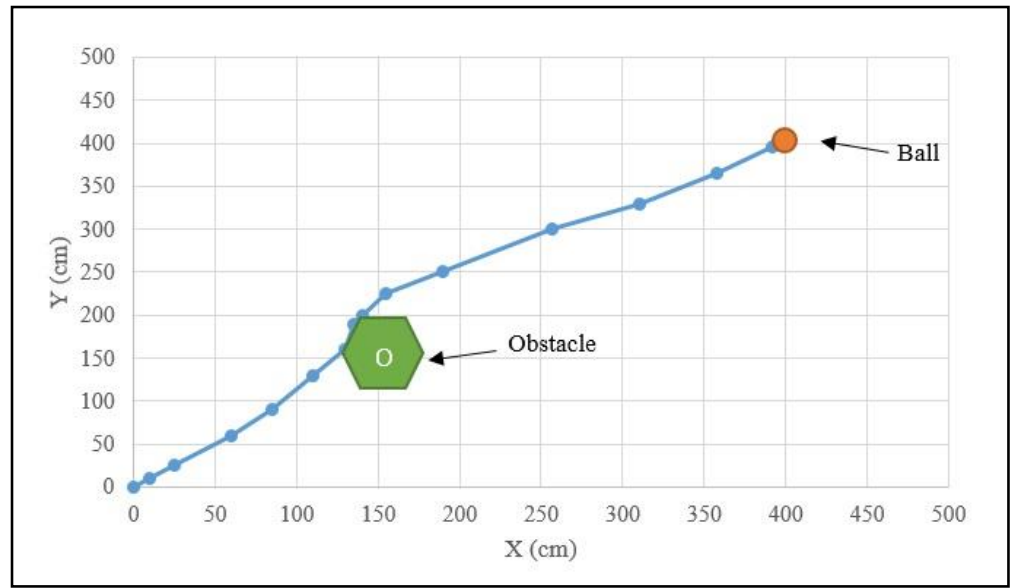

Fig. 12. The robot path sans Fuzzy Controller

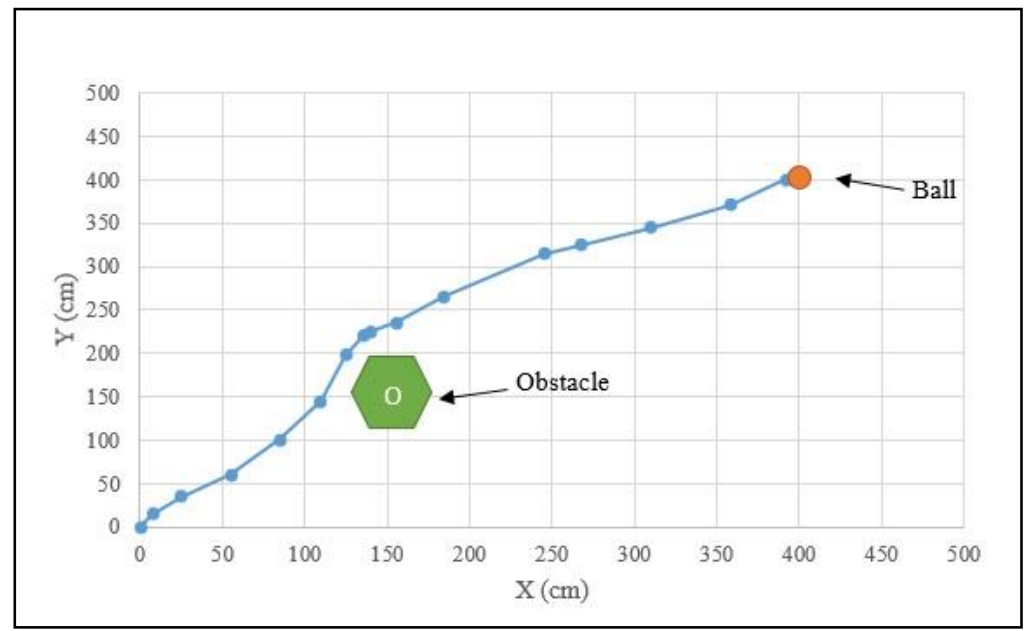

Fig. 13. The Fuzzy Controller trajectory 
Vol. 5, No. 1, Juni 2019, pp. 26-35

\begin{tabular}{ccc}
\multicolumn{3}{c}{ Table 3. The time performance comparison } \\
\hline No. & Normal control (second) & Fuzzy Control (second) \\
\hline 1 & 12.5 & 9.7 \\
2 & 11.8 & 10.5 \\
3 & 10.5 & 11.3 \\
4 & 14.3 & 8.9 \\
5 & 12.9 & 7.5 \\
6 & 13.3 & 6.5 \\
7 & 15.1 & 8.8 \\
8 & 15.8 & 7.1 \\
9 & 16.2 & 10.9 \\
10 & 14.6 & 9.1 \\
\hline Average & $\mathbf{1 3 . 7}$ & $\mathbf{9 . 0 3}$ \\
\hline
\end{tabular}

\section{CONCLUSION}

According to the experiment result in this research, wheeled soccer robot with fuzzy logic controller method that achieved mean performance both of task is obstacle avoidance of $80 \%$ and the ball caught of $70 \%$. So, external light intensity and processor units that influenced the robot performance. To improve it, recalibrating the Omni-camera would be either solution. Besides, the time average of the robot movement shown the fuzzy controller of 4.67 seconds that faster than a normal controller.

\section{REFERENCES}

[1] A. Jiang, X. Yao, and J. Zhou, "Research on path planning of real-time obstacle avoidance of mechanical arm based on genetic algorithm," Journal of Engineereing., vol. 2018, no. 16, pp. 1579-1586, 2018, doi: 10.1049/joe.2018.8266.

[2] M. Furci, D. Bicego, and A. Franchi, "Design and Input Allocation for Robots with Saturated Inputs via Genetic Algorithms," IFAC-PapersOnLine, vol. 51, no. 22, pp. 459-464, 2018, doi: 10.1016/j.ifacol.2018.11.591.

[3] P. P. Rebouças Filho, S. P. Suane, V. N. Praxedes, J. Hemanth, and V. H. C. de Albuquerque, "Control of singularity trajectory tracking for robotic manipulator by genetic algorithms,"Journal of Computational Science., vol. 30, pp. 55-64, 2019, doi: 10.1016/j.jocs.2018.11.006.

[4] R. Y. Putra et al., "Neural network implementation for invers kinematic model of arm drawing robot," in 2016 International Symposium on Electronics and Smart Devices, ISESD 2016, 2017, pp. 153-157, doi: 10.1016/j.jocs.2018.11.006.

[5] J. Yu, J. Ji, Z. Miao, and J. Zhou, "Neural network-based region reaching formation control for multi-robot systems in obstacle environment," Neurocomputing, vol. 333, pp. 11-21, 2019, doi: 10.1016/j.neucom.2018.12.051.

[6] ByungSoo Ko, Ho-Jin Choi, C. Hong, J. Kim, Oh Chul Kwon, and C. D. Yoo, "Neural network-based autonomous navigation for a homecare mobile robot," in 2017 IEEE International Conference on Big Data and Smart Computing (BigComp), pp. 403-406, 2017, doi: 10.1109/BIGCOMP.2017.7881744.

[7] L. Kong, W. He, C. Yang, Z. Li, and C. Sun, "Adaptive Fuzzy Control for Coordinated Multiple Robots With Constraint Using Impedance Learning," IEEE Trans. Cybern., vol. 49, no. 8, pp. 3052-3063, Aug. 2019, doi: 10.1109/TCYB.2018.2838573.

[8] M. A. Al Mamun, M. T. Nasir, and A. Khayyat, "Embedded System for Motion Control of an Omnidirectional Mobile Robot," IEEE Access, vol. 6, pp. 6722-6739, 2018, doi: 10.1109/ACCESS.2018.2794441.

[9] J. C. Mohanta and A. Keshari, "A knowledge based fuzzy-probabilistic roadmap method for mobile robot navigation," Applied Soft Computing., vol. 79, pp. 391-409, 2019, doi: 10.1016/j.asoc.2019.03.055.

[10] A. Shitsukane, W. Cheruiyot, C. Otieno, and M. Mvurya, "Fuzzy Logic Sensor Fusion for Obstacle Avoidance Mobile Robot," in 2018 IST-Africa Week Conference (IST-Africa), p.p 1-8, 2018, doi: Google Scholar.

[11] A. O. Pizarro-Lerma, R. García-Hernández, and V. A. Santibáñez, "Fine-Tuning of a Fuzzy Computed-Torque Control for a 2-DOF Robot via Genetic Algorithms," IFAC-PapersOnLine, vol. 51, no. 13, pp. 326-331, 2018, doi: 10.1016/j.ifacol.2018.07.299.

[12] H. Wang, J. Duan, M. Wang, J. Zhao, and Z. Dong, "Research on Robot Path Planning Based on Fuzzy Neural Network Algorithm," in 2018 IEEE 3rd Advanced Information Technology, Electronic and Automation Control Conference (IAEAC), pp. 1800-1803, 2018, doi: 10.1109/IAEAC.2018.8577599.

[13] D. R. Bruno, N. Marranghello, F. S. Osorio, and A. S. Pereira, "Neurogenetic algorithm applied to Route Planning for Autonomous Mobile Robots," in 2018 International Joint Conference on Neural Networks (IJCNN), pp. 1-8, 2018, doi: 10.1109/IJCNN.2018.8489137.

[14] Rahib H. Abiyev, Irfan S. Günsel, Nurullah Akkaya, Ersin Aytac, Ahmet Çağman, Sanan Abizada, "Fuzzy control of omnidirectional robot," Procedia Computer Science,"Volume 120, pp. 608-616, 2017, doi: 10.1016/j.procs.2017.11.286.

[15] A. Ansari and A. A. Bakar, "A Comparative Study of Three Artificial Intelligence Techniques: Genetic Algorithm, Neural Network, and Fuzzy Logic, on Scheduling Problem," 2014 4th International Conference on Artificial 
Intelligence with Applications in Engineering and Technology, Kota Kinabalu, pp. 31-36, 2014, doi: 10.1109/ICAIET.2014.15 